\title{
Sonic horror
}

Isabella van Elferen

\section{Sounds of horror}

A harpsichord in an old movie.

Approaching footsteps in the dark.

An owl hooting.

A dentist's drill.

Whispering.

Silence.

Horror film and television are more bearable with the sound turned off. Mute, the screened obscenities are merely onscreen and obscene. At a distance, staged, removed; hyper-visible, repulsive, abject. Not a threat, not a reason to be frightened. Turn the sound back on, and all of a sudden the harpsichord tells me that something is going to happen. Footsteps seem to come from within my own house, seem to approach me. The owl hoots just outside my window. 
Offscreen, in day-to-day life, horror sounds are more pervasive and more terrifying than when screens and narrative offer protection from their horrific force. At the dentist's my physical pain may be blanketed by local anaesthetics, but the sound of the drill is in my head, invasive suggestion of a horror that I cannot see and do not feel. Dreaming confused dreams of dilapidated graveyards bathing in moonlight, I wake up with a start. Did I hear someone moving about downstairs? Was that an owl hooting or a human screaming outside? Was that a whisper at my shoulder?

Or maybe there is only silence in this darkness.

No sound, not a breath of life.

Nothing.

\section{The horror of sound}

Sound is unseen. Not the confrontation with the horrific itself but the anticipation of that meeting that frightens us most. Consisting of invisible waves in the air, sound renders this anxious anticipation tangible, can even conjure it up. The sound of footsteps announcing an eye-to-eye with a monster, the creaking door as an uninvited visitor lets himself in, the foreboding sound of the dentist's drill while we sit in the waiting room. Because we cannot see the source of these sounds, our synesthetic imagination will project its own repressed fears onto that invisible entity. 
Sound can be a vehicle of the Freudian uncanny: the more anxious we are, the more certain we imagine we are that the sound is made by the entity that haunts our dreams and our nightmares. Had I dreamt of sunshine and green hilltops I would have recognized those sounds downstairs for the dishwasher. Heathcliff would have identified Cathy's knocking as a branch in the wind had he gone to sleep in a more cheerful mood. But neither I nor Heathcliff were feeling very well in the first place, we both heard something that is invisible to the eye, and we both assumed that our darkest dreams had come true.

The repressed returns when we least expect it. Invisible, it moves in darkness: but if we listen carefully we may hear it just behind us.

Shhh - was that a sound?

When circumstances make us apprehensive we expect the sounds we hear to emanate from the uncanny cause of our dread. Horror fiction and cinema, of course, manipulate readers and viewers into precisely such an apprehensive mood. Fed by ghost stories or by cameras tilting up a dark staircase, audiences are easily frightened by sound effects.

There seemed a strange stillness over everything; but as I listened I heard, as if from down below in the valley, the howling of many wolves. The count's eyes gleamed, and he said: 'Listen to them - the children of the night. What music they make!' (Stoker 1997: 24)

Dracula's comments could have been a poetic wildlife observation, but the castle is dark, the count is sinister, and the beasts cannot be seen but only heard. Sound is invisible, it creeps up on us, and if we are feeling anxious such invisible creeping cannot but spook us.

Horror film composing is entirely based on the fact that sound's invisibility can cause nervous apprehension. Sound in horror cinema and television functions as a foreboding, a 
suggestion of unseen and undefined but imminent horror. Angelo Badalamenti's ominous synthesizer chords for Twin Peaks, for instance, seem to indicate the unseen, unnameable evil that dwells in the sepia-toned hometown of Laura Palmer. Played at low volume and lacking grand musical gestures, these unassuming chords linger in airy emptiness, their near inaudibility the reason for their pervasiveness. Their sustained unobtrusiveness is a precise auditory reflection of the disconcertingly hazy atmosphere of the series. Neither Twin Peaks nor its soundtrack are going to explain the secrets of the Black and White Lodge - we have to imagine them ourselves. In The Blair Witch Project, diegetic sound is the major source of horror. ${ }^{1}$ Sighs, shrieks and forest sounds emanate from the dark forest around the protagonists but never ever show their face. The viewer must imagine the origin of these terrible sounds, and in the process must confront her own darkest fears. The source of any form of horror lies within ourselves: the platitude is repeated, reinvented, reverberated by sound.

Sound's relation to the unseen-uncanny can be described in terms of dorsality: that which is behind our back: the invisible, sinister, sinister presence that just escapes our peripheral vision when we turn around. Bypassing vision, the dorsal is only perceivable when we pay close attention to unusual smells and unfamiliar but inconspicuous sounds like whispers, rumbles, and murmurs (Wills 2008: 12). Sound is dorsal in and of itself, which is why it is such a supremely adequate means to express and evoke the anxious suspense that is central to horror's performativity.

Sound is unembodied. The invisibility of sound calls into question its materiality. Sound is made by human bodies or by objects, and sound waves move in acoustic spaces whose material shape inform their timbre. Sound, moreover, has concrete physical effects: subbasses can be felt as much as heard, a dentist's drill tangibly re-embodies the drill's sound into my own head. And yet sound is not just invisible but seemingly immaterial. We often 
hear sound rather than perceive its physical origin: bird song, trains passing, echoes. But in those cases we know that that origin is there, because there is no sound without physical source.

Except for sounds made by ghosts.

Horror hones in on sound's curious relation with materiality. Constantly asking audiences to verify the origins of the sounds they prominently feature, and relentlessly confirming that there is no origin, the genre is pervaded by unembodied sounds. Ghostly voices, such as the forest sounds in the Blair Witch Project or the chilling female voice calling 'Get away from me!' through the dark vaults of psychological horror game Amnesia, never fail to frighten audiences. But while ghosts at least are the remnants of what once was a physical body, there are other sounds that seem to have no origin at all. In Mark Z. Danielewski's House of Leaves, for instance, a growl is heard from the cold darkness of those endlessly expanding walls and rooms.

Navidson keeps his attention focused on the floor ahead of him, and no doubt because he keeps looking down, the floor begins to assume a new meaning. It can no longer be taken for granted. Perhaps something lies beneath it. Perhaps it will open up into some deep fissure.

Suddenly immutable silence rushes in to replace what had momentarily shattered it. Navidson freezes, unsure whether or not he really just heard something growl.

(Danielewski 2001: 67)

The sound only appears once or twice in the book, and it never becomes clear what causes it. At first it seems to be the sound of the walls moving, the building changing, but later on Navidson's companion Holloway 'seems to transfigure the sound into an utterance made by 
some definitive creature, thus providing him with something concrete to pursue' (Danielewski 2001123-4). Sound without physical source is unacceptably horrific, and Danielewski's indirect, almost casual description of it is eerily adequate. More importantly perhaps, this sound appears in the written word alone, and is only ever heard in the reader's mind. Unembodied, indirect, unheard: the House's growl is a vortex sucking the reader into the unhomely depths of nameless fear.

The horror of sound's unembodiment provided a dark backdrop to the invention of recording technology in the late nineteenth century. The telephone, phonograph, gramophone, and later radio were able to detach sound from its origin in order to reproduce it at later times and in other spaces. R. Murray Schafer has coined the term 'schizophonia' for the separation of sound from its origin through recording technology (Schafer 1994: 90-91). Recorded sound is physically, temporarily and spatially dislodged: recording and replaying sound means disconnecting 'live' sound from its origin, thereby making it un-live while it is also un-dead. Recorded voices are phantom voices that, like phantom pain, are the ghostly, haunting remainders of their former physical self. There are many testimonials of the suspicion and dread with which the ghostly voices of these new technologies were met. Horror cinema, and later horror television and horror videogames, exploited the disembodiment inherent to recording technology. From the spooky sounds echoing through the haunted houses of classic horror cinema to the unnerving digital noises pervading the cyberspaces of horror science fiction games, schizophonic unembodiment send shivers down viewers' very corporeal spines.

Sound is unnameable. The immaterial practice of sound's interpretation is at least as also elusive as its physical presence. Sound does not signify, it has no signified, it does not even refer: it simply sounds. Its semiotic emptiness opens it up to perpetually layered inscriptions 
of meaning. Confronted with the vacuum of signification that sound presents, listeners invent a number of ways to shun its terrifying void.

The most often-used escape route is to assume that the origin of a sound is its signified: the sound of a dog barking is taken to signify 'dog', a harpsichord timbre to signify 'harpsichord.' Layered upon this retro-active semiotic illusion, another way to avoid sound's meaninglessness is to assume that sonic connotations equate sonic meaning: a dog barking now means play, threat, or park; harpsichord timbres now mean Bach, eighteenth-century art, or horror movie. Besides the problematic equation at its basis (connotation = meaning), the weakness of this coping strategy evidently lies in its dependence on subjective associations. Play and threat are quite opposed things, and where does park come in? Who is to tell if the harpsichord means one composer's gravitas, a century's culture, or, conversely, horror soundtracks? All of the above 'meanings' coexist and are equally correct, even if they are all mere metaphors to veil the void of sonic signification. A harpsichord timbre means harpsichord and Bach and eighteenth-century culture and horror, and as many more things as there are listeners - but underneath all of that it also means nothing at all. There is no firm ground beneath our feet when it comes to sonic semiotics. And where firm ground is lacking, fear easily sets in. Sound's slippery relation to signification, reference, and meaning makes it inherently horrific.

When sound is organized into music, its ambivalent relation to visibility, materiality, time, and signification is further intensified through music's nearly infinite associativity. Much more than single sounds, music can arouse endless and highly immersive chains of connotations which emerge in listeners' memories and emotions in ways that surpass consciousness. Whether music is heard attentively or inattentively, it inevitably stirs such unconscious feelings or memories, the shadows of former listening experiences that haunt every subsequent hearing of that particular vocal timbre, that harmonic change, that melodic 
line. Music is hauntology. We do not invite its ghosts, but they will always revisit us: some music makes us sad or happy or scared simply because it was once associated with these emotions. Musical perception is a spectral funnel.

Kevin Donnelly argues that the ghostly potential of musical experience is poignantly present in film soundtracks, providing the visual narrative with a 'repository of reminders, half-memories and outbursts of emotion and the illogical, these 'ghosts' and 'memories' that can haunt a film' (Donnelly 2005: 21). It is for this reason that music lends itself to horror so easily, and that horror soundtracks can be so very immersive. The Laura Palmer chords are famously eerie precisely because they do not signify anything. These repeated chords which do not cadence but endlessly linger, the fact that they circle around a minor third with its sad reverberations, their airy timbre: their sheer emptiness forces the viewer to search her own anxious mind for the reasons why they are there and what they may mean. A dorsal commentary to the visual, the personal connotations of film and television music determine our interpretation of them. And because these connotations are subjective attempts to fill the abyss of music's real horror - that of absolute meaninglessness - we cannot be sure that the our own musical interpretations will not be proved indescribably wrong: that thumping noise which I am hoping is a heartbeat might also be that Thing lurking at the back of my mind which I will not think about. Film and television sound adds the terrifying immersion in the uncanny to film footage because its elusiveness taps into viewer's own repressed, unnameable anxieties. To the staged and framed representations of horror on screen it adds the horror of sound itself.

Sound is horror. It is unsurprising that the most terrifying moments in horror literature, film and television are sonic. Unseen, unembodied, unnameable: sound itself is at the heart of horror. 
That hooting sound may have been an owl, but I did not see the owl. It may have been something or someone pretending to be an owl, or it may have been the ghost of an owl. The sound's connotations of dense forests and nocturnal cemeteries have been rubbed in by countless horror films, but they are too vague to make sense, and the fact that they are not real makes me more anxious. If only I knew what the sound was or what it meant.

Maybe I do know.

Or maybe I heard nothing at all.

Silence, as sound's impenetrably dark, inconceivably hollow, categorically unknowable mirror image, is sublimated terror. 'There seemed a strange stillness over everything'-

\section{Sonic horror}

'The spectre of sound', as Donnelly calls it, creeps up on us dorsally, evading the relative comfort of visual recognition. Whether through whispers darkly, in the sinister connotations of the harpsichord timbre, or in the void of complete silence, horror's performativity relies on sonic guises. This Horror Studies special issue reflects the medial variation and genrecrossing possibility of unseen terror, including essays on literature, radio, film, popular music, as well as an original creation in the shape of a poem.

Sonic Horror's auditory tour of terror begins without actual sound: the first three articles discuss sound in Gothic and horror literature. Considering that literature is a silent medium, this genre of fiction devotes a remarkably large amount of space to the textual description of sound. Matt Foley's article "My voice shall ring in your ears': the acousmatic voice and the timbral sublime in the Gothic Romance' traces the role of disembodied voices as a means of auditory persecution in Gothic literature. Combining Mladen Dolar's reading of 
the voice as identity with Longinus's version of the sublime, Foley argues that Gothic Romance employs the acousmatic voice as an enduringly Other, horrific, and, in this, sublime form of excess. In 'Sound and silence: the aesthetics of the auditory in the novels of Ann Radcliffe,' Joan Passey argues that Radcliffe uses sound to generate terror in response to eighteenth-century concepts of sensibility and permeability of the self. Sound presented somewhat of a mystery to the age of sense and sensitivity: it is invisible and disembodied but nevertheless able to physically penetrate the hearing body. Passey contends that this unease with sound's sensual perception was representative of contemporary anxieties regarding societal decline. The next essay, Frances Clarke's 'Gothic vibrations and Edgar Allan Poe,' bridges the views expressed in the previous two articles: it proposes that sound is sublime because of its elusive but undeniable physicality. Clarke explores the role of sonic vibrations in Poe's work, arguing that sound sets in motion the oscillations of affect, time, reality and the supernatural which define Poe's idiosyncratic version of the Gothic.

Perched between the two larger sections on horror literature and horror cinema like a radio interlude, Danielle Hancock's 'Welcome to Welcome to Night Vale: First Steps in Exploring the Horror Podcast' discusses the thin line between comedy and horror in the un/homely world of podcasting. Welcome to Night Vale establishes an imagined collective comprize of isolated podcasters and the comical inhabitants of Night Vale. Comedy turns into horror, Hancock argues, when listeners are implicated in weird and horrific events in Night Vale through the presenter's explicit crossing of the boundaries between (podcast) fiction and (listeners') reality.

The following three essays discuss the ways in which sound adds layers of terror to the visual medium of film. Differently than in traditional discussions of horror film sound, though, these articles do not so much describe composed film soundtracks as consider sound an inherent part of the horror dispositif in cinema. Jessica Balanzategui's 'Haunted nostalgia 
and the aesthetics of technological decay: hauntology and Super 8 in Sinister.' The 2012 film Sinister creates a horror that Balanzategui describes as a 'monstrous corruption' of the nostalgic gaze of the Super 8 camera. As the anachronistic Super 8 imagery gradually consumes the digital visuals, the film's sinister hauntology is strengthened by the layering of diegetic and non-diegetic sounds. Like Welcome to Night Vale, Sinister creeps into its audience's private space, and like the podcast, this movie achieves that effect by way of sound. Steven T. Brown's article 'Ambient horror: from sonic palimpsests to haptic sonority in the cinema of Kurosawa Kiyoshi' discusses the sound of Japanese horror cinema, which is often described as far more frightening than Hollywood horror. Brown explores the ways in which J-horror soundtracks achieve this effect by analysing Kiyoshi's nonlinear microsounds, his negotiations of silence, and - in a line of argument not dissimilar to Frances Clarkes's on Poe - the haptic touch of horrific sound waves. The last article in this section, Sean Matharoo's “A weird creature operating in the theater': Cult, synaesthesia and the ethicopolitics of horror in Danny Perez and Animal Collective's $O D D S A C^{\prime}$, discusses the cult film version of cult album $O D D S A C$. Consisting of a wild synesthetic blend of music, horror film clips, samples from horror soundtracks, and electronic noise, Matharoo argues, this film presents a kaleidoscopic contemporary version of Lovecraftian cosmic horror.

Besides underground noise bands, other popular music genres, too have a long histories of quoting, sampling, and emulating horror cinema. Amanda DiGoia's article 'A cry in the dark: the howls of wolves in horror and heavy metal music' zooms in on a specific area in the field of horror rock: the ways in which metal music employs the 'sweet music' of 'the children of the night'. After an exploration of the biology of howling and the history of its connection to the horror genre, DiGoia discusses the role of howling in a number of metal tracks. She argues that howling, whether in song lyrics, in vocal performance, or in samples, 
functions as the communication of emotional or identity content: metal, in this sense, follows the biological function of lupine communication.

The two final contributions each wrap up the themes discussed in this special issue. Theorising monsters, sound, and sound-as-monstrosity, my 'Sonic monstrosity,' offers an overview of sonic horror across literature, film, television, and videogames. Because sonic media share the dorsality that is characterizes horror's monsters, the essay argues, they are not just able to accompany or represent horror: sound is inherently a form of monstrosity, a form of horror. Phil Emery's poem 'Nosfera-2,' finally, takes the reader past the stages of this special issue's sonic horror journey. It sketches early vampire takes and their screen appearances. It talks about sound and hearing sound. It reflects on the absence of sound in silence, and on the horror of the absence of sound in silence. Itself a poem, the written but not spoken word, this text whispers the great paradox that haunts this journal issue: in writing no one can hear you scream.

But perhaps Emery's silent scream offers a glimpse of the yet unheard. 


\section{References}

Danielewski, Mark Z. (2001), House of Leaves, London/New York: Doubleday.

Donnelly, Kevin J. (2005), The Spectre of Sound: Music in Film and Television, London:

British Film Institute.

Schafer, R. Murray (1994), The Soundscape: Our Sonic Environment and the Tuning of the World, Rochester, New York: Destiny.

Stoker, Bram (1997), Dracula, New York: Norton.

Wills, David (2008), Dorsality: Thinking Back through Technology and Politics, Minneapolis: University of Minnesota Press.

\footnotetext{
${ }^{1}$ Diegetic sound, like the Blair Witch screams, originates within the film or television world; non-diegetic sound, like Twin Peaks's synthesizer chords, is heard only by the viewers.
} 